\title{
Textura do solo e a estimativa do teor de água no ponto de murcha permanente com psicrômetro
}

\author{
Soil texture and the estimation by Dewpoint Potential Meter of water retention at wilting point
}

\author{
Vilson Antonio Klein ${ }^{\mathrm{I}}$ Matheus Baseggio ${ }^{\mathrm{II}}$ Tiago Madalosso ${ }^{\mathrm{II}}$ Clóvis Darli Marcolin ${ }^{\mathrm{III}}$
}

\section{RESUMO}

A determinação do volume de água disponível às plantas é fundamental para o correto manejo da irrigação $e$ definição quanto ao uso dos solos agrícolas. Os principais fatores que exercem influência na retenção e disponibilidade de água às plantas são a textura e a estrutura do solo. $O$ objetivo deste trabalho foi quantificar a influência da textura na retenção da água, na condição de ponto de murcha permanente $(P M P)$ das plantas $(-1,5 M P a)$, sendo utilizado um psicrômetro modelo WP4-T. Determinaram-se a textura de 100 amostras de solo e o teor de água no PMP. Os resultados indicaram que, em potenciais maiores que -1,0MPa, o psicrômetro mostrou-se pouco preciso, não se recomendando a sua utilização nessa condição. O PMP aumentou de 0,059 para $0,29 \mathrm{~g} \mathrm{~g}^{-1}$, quando o teor de argila aumentou de 120 para $779 \mathrm{~g} \mathrm{~kg}^{-1}$. Obteve-se um bom ajuste dos resultados do teor de água no PMP em função do teor de argila do solo, e 91\% da variação do teor de água no PMP puderam ser atribuídos à variação no teor de argila. Conclui-se que o psicrômetro é um equipamento que pode ser utilizado para determinar o PMP, e a equação PMP $\left(\mathrm{g} \mathrm{g} \mathrm{g}^{-1}\right)=0,0003 *$ Argila $\left(\mathrm{g} \mathrm{kg}^{-1}\right)+0,0118$ pode ser utilizada para estimar o PMP.

Palavras-chave: retenção de água no solo, teor de argila, potencial da água no solo.

\section{ABSTRACT}

The determination of the available water to plants is essential to right irrigation management and definition regarding the use in agricultural soils. The main factors that exert influence on retention and availability of water to plants are texture and soil structure. The aim of this study was to quantify the influence of the texture on water retention in the condition of permanent wilting point $(P W P)$ of plants $(-1,5 M P a)$ using a WP4-T Dewpoint Potentia Meter. The texture of 100 soil sample and soil moisture at PWP was determined. Results indicated that, in potentials higher than -1,0MPa, WP4-T seemed not very precise, therefore its use is not recommended in this condition. PWP increased from 0,059 to $0,29 \mathrm{~g} \mathrm{~g}^{-1}$, while the clay content increased from 120 to $779 \mathrm{~g} \mathrm{~kg}^{-1}$. It was obtained a good adjustment of the results of water content at PWP based on clay content of soil, being that $91 \%$ of variation in water content at PWP could be attributed to variation in clay content. It was concluded that WP4-T is an equipment that can be used to determine PWP and the equation PWP $\left(\mathrm{g} \mathrm{g}^{-1}\right)=0,0003 *$ Clay $\left(\mathrm{g} \mathrm{kg}^{-1}\right)+0,0118$ can be used to estimate PWP.

Key words: soil water retention, clay content, soil water potential.

\section{INTRODUÇÃO}

O solo, reservatório de água às plantas, é afetado pelo seu manejo e pelas práticas culturais, com consequente alteração da dinâmica e retenção de água nos poros. Os fatores que influenciam a disponibilidade de água às culturas são: a estrutura do solo, por determinar o arranjo das partículas; a textura, o tipo e quantidade de argila e o teor de matéria orgânica (KLEIN \& LIBARDI, 2000). A textura do solo, principalmente o teor de argila, define em boa parte a distribuição do diâmetro dos poros do solo, determinando assim a área de contato entre as partículas sólidas e a água, sendo por isso responsável pela força de retenção, principalmente em baixos potenciais, como aquele do ponto de murcha permanente (PMP) (REICHARDT,

IFaculdade de Agronomia e Medicina Veterinária (FAMV), Universidade de Passo Fundo (UPF), CP 611, 99001-970, Passo

Fundo, RS, Brasil. E-mail: vaklein@upf.br. *Autor para correspondência.

${ }^{\text {II } C u r s o ~ d e ~ A g r o n o m i a, ~ F A M V, ~ U P F, ~ P a s s o ~ F u n d o, ~ R S ~ B r a s i l . ~}$

"IIInstituto Federal de Educação, Ciência e Tecnologia do Rio Grande do Sul, campus de Sertão, Sertão, RS, Brasil 
1987). O teor de argila mais silte afeta de forma significativa o teor de água no PMP, enquanto a estrutura do solo tem menor influência na retenção da água nesse ponto (ARRUDA et al., 1987). BELL \& VAN KEULEN (1995) encontraram equações com bom ajuste para PMP em função do teor de argila.

A determinação do efetivo volume de água disponível (AD) para as plantas continua sendo um grande desafio para a ciência do solo, uma vez que é indispensável para o correto manejo da água e a orientação de projetos de irrigação. AD é definida como teor de água do solo contido entre a capacidade de campo (CC) e o PMP. A grande dificuldade é estabelecer critérios quanto à definição dos teores no qual o solo se encontra na CC e no PMP (KLEIN, 2008).

O PMP é o teor de água de um solo no qual as folhas de uma planta que nele cresce atingem um murchamento irrecuperável, mesmo quando colocada em uma atmosfera saturada com vapor de água (VIEHMEYER \& HENDRICKSON, 1949). O PMP representa, portanto, o teor de água mínima disponível no solo para o desenvolvimento das plantas (BRIGGS \& SHANTZ, 1912). O valor prático da determinação do PMP, segundo ARRUDA et al. (1987), é reduzido, servindo apenas como um guia geral do limite inferior de disponibilidade de água às plantas. A determinação do PMP é complicada e seu valor apenas uma referência, visto que os sintomas de murchamento na planta com consequente decréscimo da produção ocorrem muito antes que a tensão da água no solo atinja o PMP, porém a atividade vegetal só é cessada após atingir esse ponto (RICHARDS \& WALDLEIGH, 1952; ARRUDA et al., 1987; JONG VAN LIER, 2000).

Com bases nesse conceito, introduzido no início do século passado, o PMP é uma grandeza física de um solo, estimada pelo teor de água retida no potencial matricial, de aproximadamente $-1,5 \mathrm{MPa}$ (HILLEL, 1980; ROMANO \& SANTINI, 2002), pois em baixo potencial o teor de água no solo varia pouco. Para tal determinação em laboratório, utilizam-se as câmaras de Richards e, mais recentemente, o psicrômetro, sendo que o modelo WP4-T apresenta, em relação aos demais, um sistema eficiente de controle e manutenção da temperatura no interior da câmara, facilitando o equilíbrio da temperatura da amostra de solo com o interior do equipamento. O princípio da determinação do potencial da água na amostra de solo é obtido pelo somatório de potencial mátrico e osmótico (SCANLON et al., 2002).

O potencial da água em uma amostra sólida ou líquida pode ser obtido relacionando-se o potencial de água da amostra com a pressão do vapor do ar em equilíbrio com a amostra. A pressão de vapor do ar pode ser medida utilizando-se um espelho resfriado, e a saturação da pressão de vapor em dada temperatura pode ser determinada por meio de um sensor ótico (DECAGON, 2003). As câmaras de Richards apresentam alguns problemas na sua utilização. Por serem caras, dependerem de um complexo sistema pneumático, as placas porosas são frágeis e nem sempre é obtido o contato perfeito entre a amostra de solo e a placa. Outro problema é a demora nas determinações em função do lento equilíbrio do potencial da água na amostra, o que em solos argilosos pode ultrapassar 45 dias (KLEIN, 2008). Em função desses inconvenientes das câmaras de Richards, a utilização do psicrômetro WP4-T vem se disseminando devido à rapidez nas determinações. No entanto, em função do princípio de funcionamento, baseado na Equação de Kelvin, a qual é dependente da pressão de vapor do líquido, a utilização para determinação em elevados potenciais é imprecisa (KLEIN \& MARCOLIN, 2008) e pode ser afetada pela estrutura e pela textura do solo.

Os objetivos deste trabalho foram avaliar o psicrômetro WP4-T para determinação do teor de água no PMP e determinar a influência da textura no teor de água do solo nessa condição.

\section{MATERIAL E MÉTODOS}

Dez amostras de terra fina seca ao ar de um Latossolo Vermelho Distrófico típico com $580 \mathrm{~g} \mathrm{~kg}^{-1}$ de argila foram colocadas em cilindros metálicos de $5 \mathrm{~cm}$ de diâmetro e $100 \mathrm{~cm}^{-3}$, saturados e submetidos a potenciais decrescentes de -0,001 até -0,10MPa, sendo utilizados funis de placa porosa e câmaras de Richards para determinar o teor de água nos distintos potenciais. Esse mesmo solo foi colocado em cápsulas de metal e foi determinado o potencial de água no solo utilizando o psicrômetro WP4-T, a fim de comparar os resultados do psicrômetro com metodologias tradicionais, como funis de placa porosa e câmaras de Richard.

Para avaliar o efeito da textura sobre o teor de água no solo no PMP, 100 amostras de solos foram coletadas nos Estados do Rio Grande do Sul e de Santa Catarina e analisadas quanto a sua composição granulométrica e o teor de água no potencial de 1,5MPa. A análise granulométrica foi realizada com a utilização de dispersante hidróxido de sódio e hexametafosfato de sódio, de agitação mecânica por 15h, e do método da pipeta para determinação das frações granulométricas (RUIZ, 2005).

O psicrômetro modelo WP4-T, marca Decagon $^{\circledR}$ Devices $^{\circledR}$, consta de um sistema cuja gaveta conduz uma amostra de solo úmido, com estrutura deformada, para dentro de uma câmara hermeticamente 
fechada. A umidade na câmara equilibra-se com o potencial da água no solo, sendo este calculado com base na temperatura do solo e do ar, no ponto de orvalho (SCANLON et al., 2002). Cerca de três gramas de terra fina seca ao ar são colocados em cápsulas de aço inox com dimensões internas de 37,2mm de diâmetro e 9,7mm de altura. Dentro da cápsula, o solo é umedecido e, em seguida, fecha-se a cápsula com uma tampa de plástico, que permanece por $24 \mathrm{~h}$ para que ocorra a perfeita redistribuição da água em toda a amostra. Com a finalidade de evitar a contaminação interna do equipamento, comprime-se levemente a amostra. O procedimento consiste em colocar a cápsula na gaveta, e nesse instante o equipamento determina a temperatura da amostra de solo e do interior do psicrômetro. Quando a temperatura da amostra é mais fria do que o ar, esta é aquecida automaticamente por um bloco aquecedor até que ocorra o equilíbrio, enquanto que, se a amostra estiver mais quente do que o ar do interior do aparelho, este apresenta uma mensagem "amostra muito quente”, não permitindo a análise. Assim, para agilizar as análises, é importante que a temperatura da amostra de solo e do interior do psicrômetro seja próxima. Isso é obtido trabalhando-se em ambiente com temperatura e umidade relativa controladas. Quando existe a necessidade do equilíbrio entre a temperatura da amostra de solo e do ar da câmara do equipamento, as determinações são mais demoradas.

A vantagem da utilização da cápsula de metal em relação à de plástico é que esta permite realizar várias determinações de potencial de água no solo e posterior pesagem. Após a realização dessas determinações, a amostra é levada para estufa a $105^{\circ} \mathrm{C}$, para se obter o teor de água à base de massa dos vários potenciais. A partir de um conjunto de pontos de potencial e teor de água, é possível obter a curva característica de dessorção da água do solo. O tempo médio de cada determinação é estimado em cinco minutos, em que são obtidos normalmente seis pontos que permitem determinar com segurança, a partir da equação de ajuste obtida, o teor de água do solo à base de massa, para o potencial de-1,5MPa (KLEIN et al., 2006).

Os resultados do teor de água dos solos em função do teor de argila e argila+silte foram ajustados com a minimização da soma do quadrado dos desvios, sendo utilizado para tal o Software SAS e verificada a soma que apresentasse o maior coeficiente de determinação e coeficiente de correlação mais significativo (teste de F).

\section{RESULTADOS E DISCUSSÃO}

Os resultados do teor de água retido nas amostras de solo pelo método da dessorção da água, por meio da aplicação de tensões nos funis de placa porosa e na Câmara de Richards (-0,001 a -0,10MPa) e da evaporação de água das amostras com a utilização do WP4-T para determinação do potencial de água no solo (-1 a -15MPa), são apresentados na Figura 1A. Enquanto o potencial variou de $-0,001$ para $-0,10 \mathrm{MPa}$, o teor de água no solo diminuiu de 0,53 para $0,23 \mathrm{~g} \mathrm{~g}^{-1}$, demonstrando a elevada concentração de poros com diâmetro equivalente que foram esvaziados com a sucção aplicada. Esses valores são compatíveis com os apresentados por KLEIN \& LIBARDI (2002), que também estudaram de forma detalhada a distribuição do diâmetro dos poros de um Latossolo sob diferentes manejos.

Observa-se também que os teores de água obtidos com o WP4-T apresentam uma elevada dispersão dos pontos para potenciais muito próximos, quando este era superior a -1,0MPa (Figura 1A). Isso comprova que efetivamente o WP4-T não pode ser utilizado com precisão para determinação do potencial de água no solo em potenciais maiores que -1,0MPa, como já havia sido destacado por KLEIN \& MARCOLIN(2008).

Com a exclusão dos pontos obtidos pelo psicrômetro em potenciais maiores que -1,0MPa, foi possível ajustar os dados para a equação de VAN GENUCHTEN (1980) em duas partes, sendo utilizado o software SWRC desenvolvido e descrito por DOURADO NETO et al. (1990) e fixado o valor do teor de água na saturação igual à porosidade total e ao teor de água resídual (Figura 1B). Um primeiro ajuste foi feito do teor de água do solo saturado até o potencial de -1,5MPa, e os parâmetros empíricos obtidos para: a $(1 / \mathrm{MPa})=870 ; \mathrm{m}=0,0908$ e $n=9,3845$ e um segundo ajuste entre os potenciais de $-1,5$ a $-15,9 \mathrm{MPa}$ o valor dos parâmetros foi: a (1/MPa)=0,3; m=0,6566 e n=1,7629. As diferenças entre valores dos parâmetros empíricos para os dois ajustes podem ser explicadas pela inclinação da curva e são compatíveis com as encontradas por KLEIN \& LIBARDI (2002). Enquanto na primeira parte há uma elevada inclinação ocasionada pela grande drenagem de água com a diminuição do potencial, na segunda parte, em função do pouco efeito da estrutura sobre a retenção de água, a variação foi muito pequena. A destacar que a variação do teor de água, enquanto o potencial variou de -1,0 e 15MPa foi de 0,18 para $0,12 \mathrm{~g} \mathrm{~g}^{-1}$.

A curva de retenção da água no solo (Figura 1B) tende a apresentar um modelo bimodal, isto é, um 


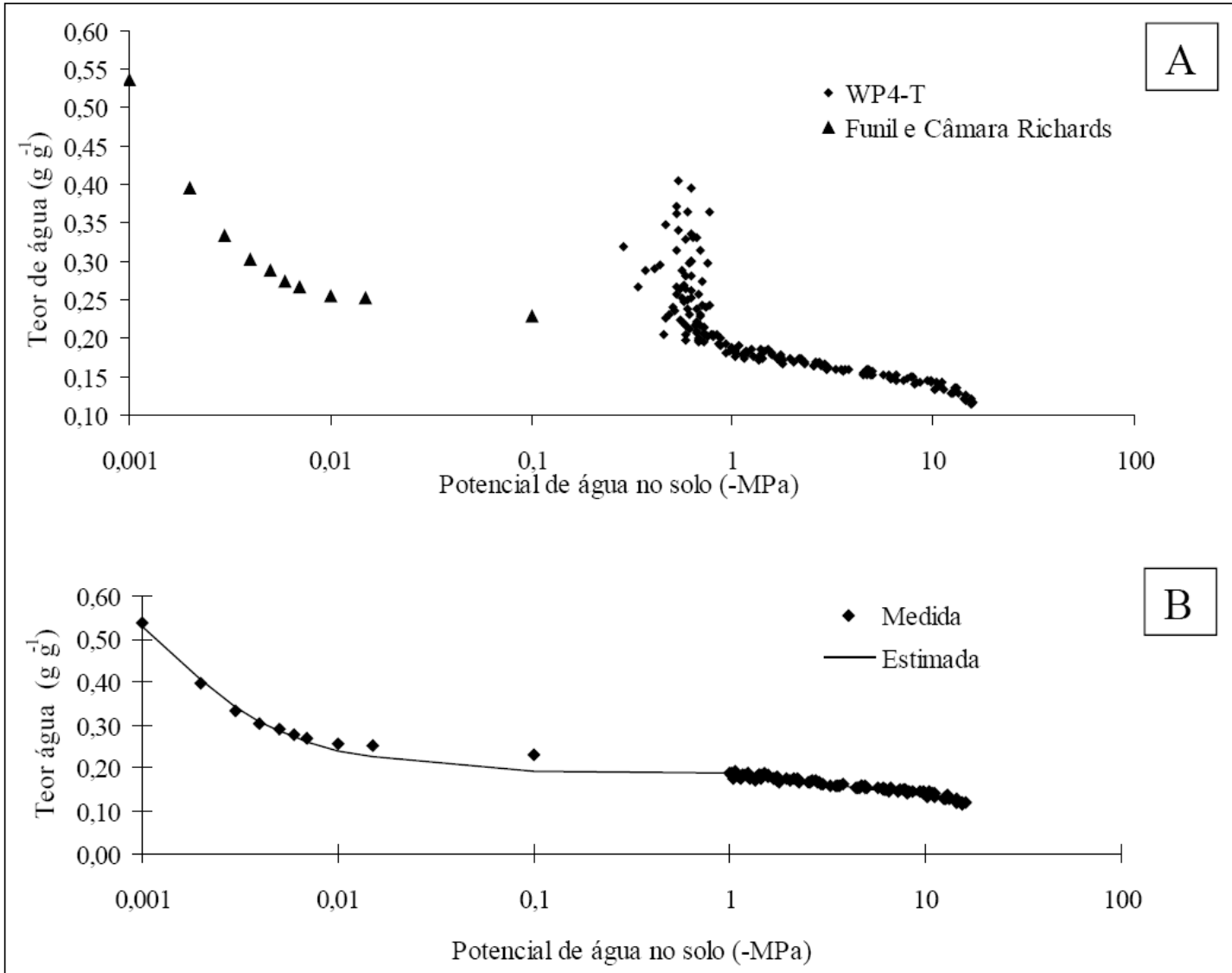

Figura 1 - Teor de água de um Latossolo Vermelho Distrófico típico em função do potencial de água determinado por duas metodologias (A) e ajuste dos pontos experimentais à equação de Van Genuchten (B).

patamar com pequena variação do teor de água entre -0,01 e -1,5MPa, condição em que o poros interagregados são esvaziados. Observa-se também uma redução do teor de água em potenciais menores que-10MPa, em que o poros intra-agregados começam a perder água (Figura 1B). Esse fenômeno foi amplamente estudado e comprovado por KERTZMANN (1996), trabalhando com porosimetria de mercúrio. De qualquer forma, o WP4-T apresentase também como uma alternativa para estudar a distribuição do diâmetro dos poros do solo nessa faixa de potencial.

Para determinação do PMP (potencial-1,5MPa), o psicrômetro WP4-T apresentou resultados satisfatórios, com umbom ajuste $\left(\mathrm{R}^{2}=0,99\right)$ (Figura 2). Essa determinação é facilitada utilizando-se as cápsulas metálicas que permitem determinações subsequentes de potencial com a mesma amostra úmida perdendo água a cada determinação, secando-a depois de ter obtido valores de potencial próximo de -1,5MPa. A partir da equação logarítmica (Figura 2) é facilmente obtido o teor de água do solo para o potencial de $-1,5 \mathrm{MPa}$, que para esse solo foi de $0,18 \mathrm{~g} \mathrm{~g}^{-1}$.
Os resultados do teor de água do solo no PMP em função do teor de argila dos 100 solos (Figura 3) apresentaram $R^{2}$ de 0,91 . Isso significa dizer que cerca de $91 \%$ da variação do teor de água do solo na condição do PMP podem ser atribuídos ao fator argila. Observase um incremento do teor de água com o aumento do teor de argila, na proporção de $0,1 \mathrm{~g} \mathrm{~g}^{-1}$ para um aumento de $294 \mathrm{~g} \mathrm{~kg}^{-1}$ no teor de argila. Compararam-se os resultados obtidos com o modelo apresentado por BELL \& VAN KEULEN (1995), em que se constata que os valores do PMP em função do teor de argila dos dados obtidos neste trabalho são inferiores aos daquele trabalho, na média, em 0,05g g-1 (Figura 3). Observa-se ainda que as retas não são praticamente paralelas, pois possuem o mesmo coeficiente angular de 0,0003; no entanto, constata-se que, com aumento no teor da argila, a diferença entre os dois modelos diminui. É preciso destacar que a metodologia utilizada para obtenção do teor de água no PMP foi distinta, uma vez que, no trabalho de BELL \& VAN KEULEN (1995), foram utilizadas as câmaras de Richards. Nesse sentido, é importante destacar que KLEIN et al. (2006) já 


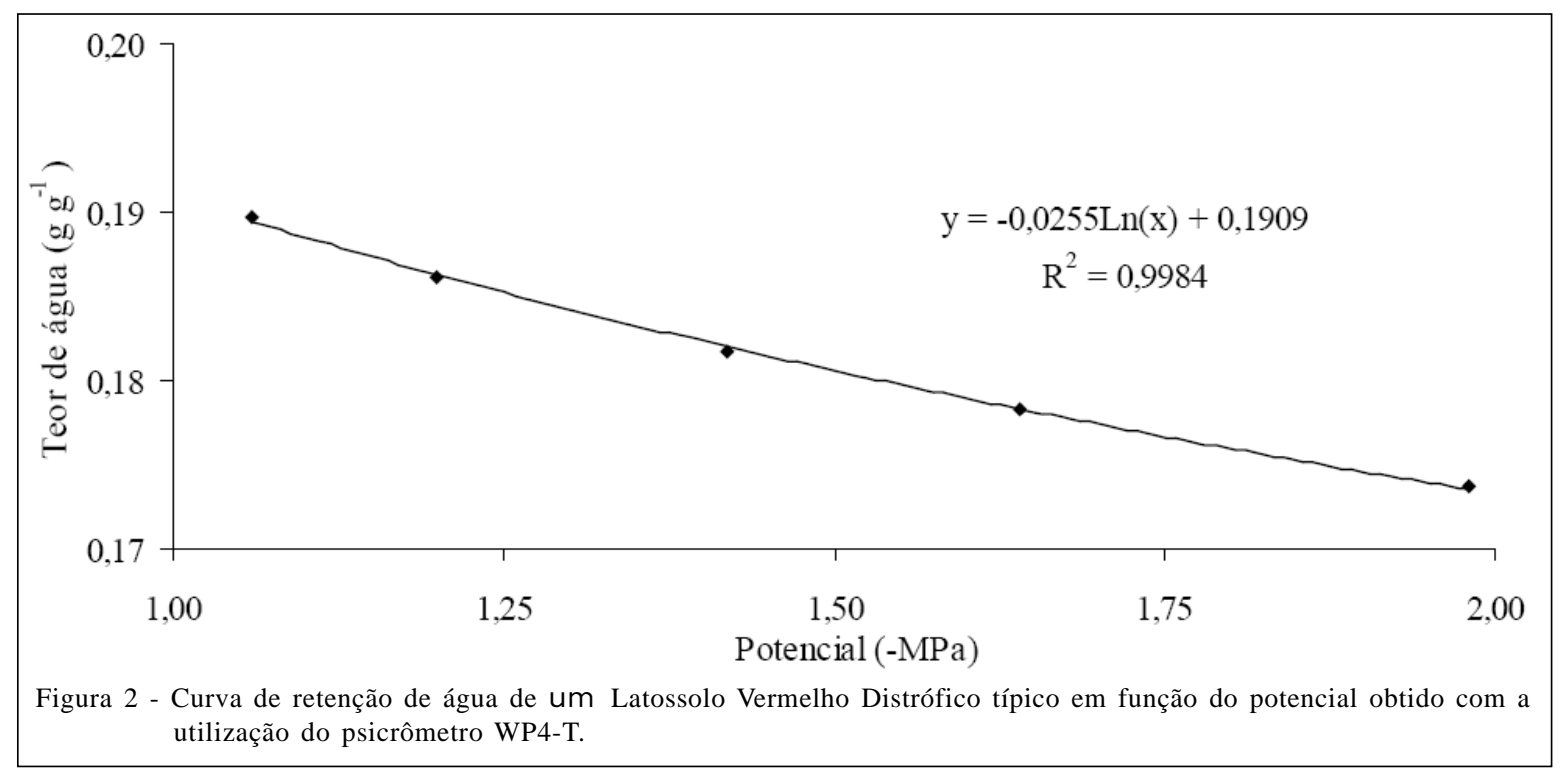

detectaram que, para um Latossolo vermelho, nas câmaras de Richards, o teor de água no PMP é cerca de 0,04g g ${ }^{-1}$ maior do que no WP4-T.

SOLANO PERAZA (2003), trabalhando com funções de pedotransferência, encontrou melhor correlação entre o teor de argila do solo e teor de água no potencial de $-1,5 \mathrm{MPa}$ para solos com atividade química da argila alta $\left(>27 \mathrm{cmol}_{c} \mathrm{dm}^{-3}\right)$, indicando também haver influência do material de origem e da mineralogia do solo na dinâmica de retenção de água. $\mathrm{O}$ ajuste do teor de água na condição de PMP, em função do teor de argila + silte (Figura 4), apresentou também um bom ajuste $\left(R^{2}=0,85\right)$, indicando que $85 \%$ da variação do teor de água no PMP podem ser atribuídos ao somatório das frações argila + silte. Em relação ao somatório argila+silte, o ajuste obtido neste trabalho é semelhante ao obtido por ARRUDA et al. (1987), apresentado na figura 4. No modelo, os autores trabalharam também num amplo intervalo (76 a $890 \mathrm{~g} \mathrm{~kg}^{-1}$ de argila + silte), mas utilizaram câmaras de Richards para determinação do PMP. As retas apresentam também certo paralelismo, com o mesmo coeficiente angular.

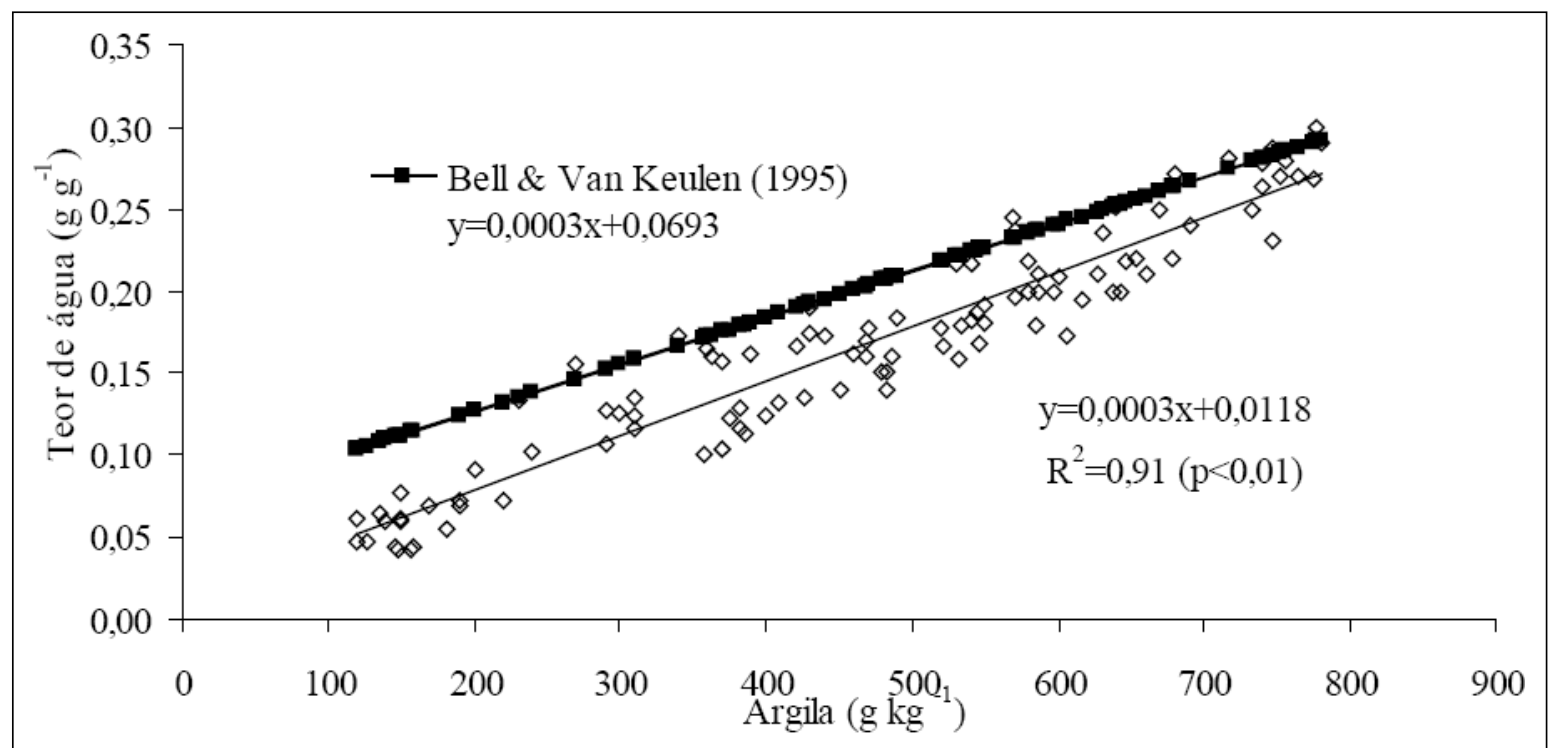

Figura 3 - Teor de água ( $\mathrm{g} \mathrm{g}^{-1}$ ) do solo no PMP em função do teor de argila obtido neste trabalho e o apresentado na literatura.

Ciência Rural, v.40, n.7, jul, 2010. 


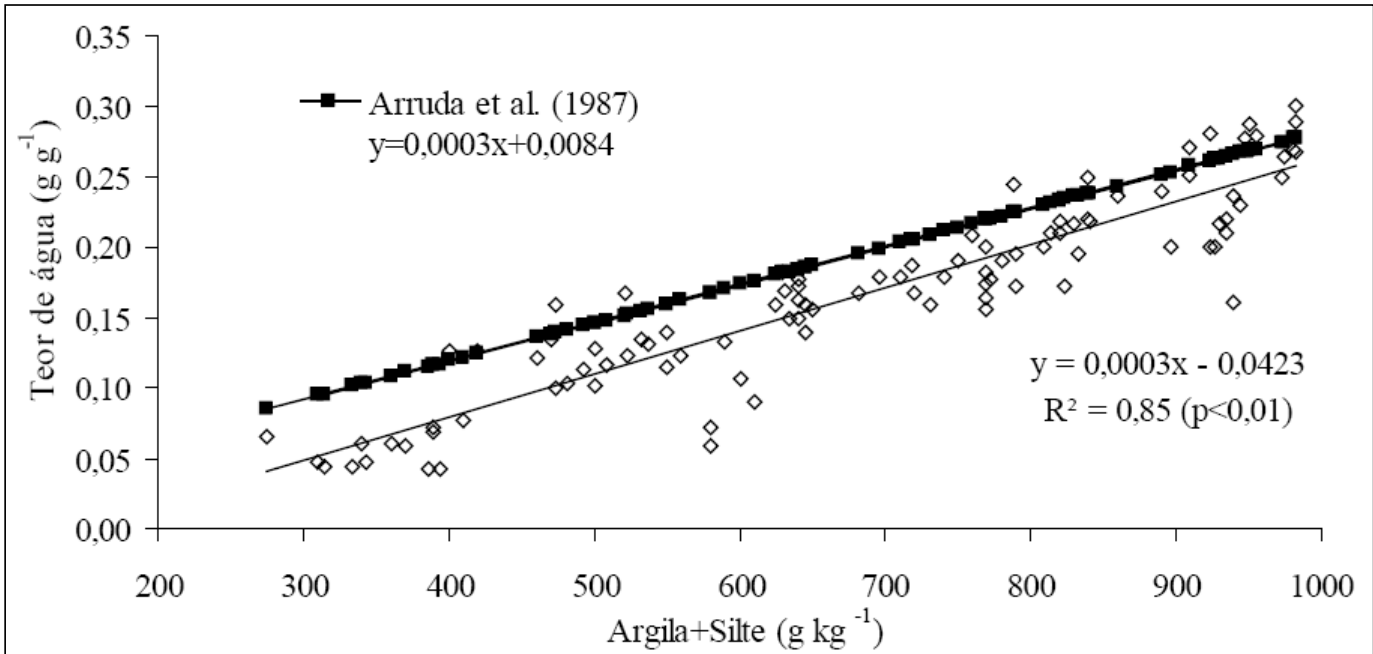

Figura 4 - Teor de água ( $\mathrm{g} \mathrm{g}^{-1}$ ) do solo no PMP em função do teor de argila + silte obtido neste trabalho e o apresentado na literatura.

Para a obtenção do PMP, a equação com menor número de variáveis é aquela da figura 3, uma vez que exige somente a determinação de argila, enquanto a da figura 4 exige a determinação de argila+silte e ainda apresenta $\mathrm{R}^{2}$ inferior àquela. Então, a equação que preferencialmente deve ser utilizada para determinaçãodoPMPé $\left(\mathrm{gg}^{-1}\right)=0,0003^{*}$ Argila $\left(\mathrm{gkg}^{-1}\right)+0,0118$.

\section{CONCLUSÃO}

O psicrômetro WP4-T é um equipamento versátil e pode ser utilizado para determinar o PMP, mas apresenta resultados pouco precisos para potenciais maiores que -1,0MPa. O teor de argila e o teor de argila+silte do solo permitem determinar o teor de água no solo no PMP, e a equação PMP( g g $\left.^{-1}\right)=0,0003^{*}$ Argila $\left(\mathrm{g} \mathrm{kg}^{-1}\right)+0,0118$ pode ser utilizada para estimar o PMP.

\section{AGRADECIMENTOS}

Ao Conselho Nacional de Desenvolvimento Científco e Tecnológico (CNPq), pelas bolsas de produtividade em pesquisa e de iniciação científica, e pelo auxílio financeiro. Ao Pibic/UPF e Pibic/Fapergs, pelas bolsas de iniciação científica.

\section{REFERÊNCIAS}

ARRUDA, F.B. et al. Parâmetros de solo para o cálculo da água disponível com base na textura do solo. Revista Brasileira de Ciência do Solo. v.11, p.11-15, 1987.

BELL, M.A.; Van KEULEN, A. Soil pedotransfer functions for four Mexican soils. Soil Science Society of American Journal, v.59, p.865-871, 1995.
BRIGGS, L.J.; SHANTZ, H.L. The wilting coefficient for different plants and its indirect determination. Washington DC. United States: Department of Agriculture, Bureau of Plant Industries, 1912. 83p. (Bulletin n.30).

DECAGON DEVICES, INC. Operator's manual version 3 WP4 Dewpoint PotentiaMeter. Pulmann: Decagon Devices, 2003. 77p.

DOURADO NETO, D. et al. Programa para confecção da curva de retenção de água no solo utilizando o modelo de Genuchten. Engenharia Rural, v.1, p.92-102, 1990.

HILLEL, D. Fundamentals of soil physics. New York: Academic, 1980. 413p.

JONG VAN LIER, Q. de. Índices da disponibilidade de água para as plantas. Tópicos em Ciência do Solo, SBCS, v.1, p.95-106, 2000.

KERTZMANN, F.F. Modificações na estrutura e no comportamento de um latossolo roxo provocadas pela compactação. 1996. 153f. Tese (Doutorado em Geografia Física) - Faculdade de Filosofia, Letras e Ciências Humanas, Universidade de São Paulo, SP.

KLEIN V. A. Física do solo. Passo Fundo: EDIUPF, 2008. 212p.

KLEIN, V.A.; LIBARDI, P.L. A faixa de umidade menos limitante ao crescimento vegetal e a sua relação com a densidade do solo ao longo de um perfil de um Latossolo roxo. Ciência Rural, v.30, p.959-964, 2000. Disponível em: <http:// www.scielo.br/scielo.php?script=sci_abstract\&pid=S0103$84782000000600006 \& \operatorname{lng}=p t \& n r m=i s o \& \operatorname{lng}=p t>$. Acesso em: 12 jun. 2010. doi: 10.1590/S0103-84782000000600006.

KLEIN, V.A.; LIBARDI, P.L. Densidade e distribuição do diâmetro dos poros de um Latossolo Vermelho, sob diferentes sistemas de uso e manejo. Revista Brasileira de Ciência do Solo, v.26, p.857-67, 2002. 
KLEIN, V.A.; MARCOLIN C.D. Utilização do psicrômetro WP4 -T para determinação do potencial da água no solo. In: REUNIÃO BRASILEIRA DE MANEJO E CONSERVAÇÃO DO SOLO E DA ÁGUA, 17., 2008, Rio de Janeiro. Anais... Rio de Janeiro: Embrapa/SBCS 2008. 1 CD-ROM.

KLEIN, V.A. et al. Água disponível em um Latossolo Vermelho argiloso e murcha fisiológica das culturas. Revista Brasileira de Engenharia Agrícola e Ambiental. v.10, p.646-650, 2006. Disponível em: <http:/ /www.scielo.br/scielo.php?script=sci_abstract\&pid=S1415$3662006000300016 \& \operatorname{lng}=p t \& n r m=$ iso\&tlng=pt $>$. Acesso em: 12 jun. 2010. doi: 10.1590/S1415-43662006000300016.

REICHARDT, K. A água em sistemas agrícolas. São Paulo: Manole, 1987. 188p.

RICHARDS, L.A.; WALDLEIGH, C.H. Soil water and plant growth. Soil physical conditions and plant growth. Madison: ASA, 1952. 31p.

RO MANO, I.; SANTINI, A. Water retention and storage: field. In: DANE, J.H.; TOPP, C. (Eds.) Methods of soil analysis. Part 4. Physical methods. Madison: Soil Science Society of America, 2002. p.721-738.
RUIZ, H.A. Incremento da exatidão da análise granulométrica do solo por meio da coleta da suspensão (silte+argila). Revista Brasileira de Ciência do Solo, v.29, p.297-300, 2005. Disponível em: <http:/ /www.scielo.br/scielo.php?script $=$ sci_abstract\&pid=S0100$06832005000200015 \& \operatorname{lng}=p t \& n r m=i s o \& \operatorname{lng}=p t>$. Acesso em: 12 jun. 2010. doi: 10.1590/S0100-06832005000200015.

SCANLON, B.R. et al. Water potential: Miscellaneous methods for measuring matric or water potential. In: DANE, J.H; TOPP, C. (Eds.) Methods of soil analysis. Part 4. Physical methods. Madison: Soil Science Society of America, 2002. p.643-670.

SOLANO PERAZA, J.E. Retenção de água e pedofunções para solos do Rio Grande do Sul. 2003. 117f. Dissertação (Mestrado em Engenharia Agrícola) - Universidade Federal de Santa Maria, Santa Maria, RS.

VAN GENUCHTEN, M.TH. A Closed-form equation for predicting the hydraulic conductivity of unsaturated soils. Soil Science Society of America Journal. v.44, p.892-897, 1980.

VIEHMEYER, F.J.;HENDRICKSON, A.H. Methods of measuring field capacity and permanent wilting percentage of soils. Soil Science, v.68, p.75-94, 1949. 